\title{
RECOMMENDATIONS FOR MEDICAL OFFICERS ATTENDING KARATE COMPETITIONS
}

\author{
G. R. MCLATCHIE, FRCS
}

\author{
Medical Officer to the Scottish Karate Board of Control, and to the British Karate Board
}

\section{INTRODUCTION}

Karate is now a popular participant pastime in Great Britain and with the governing bodies attempting to gain Olympic recognition for the sport it is important that adequate medical cover be available for competitors. It has already been shown that there is a relatively high incidence of injury in competition (McLatchie 1976) and that this can also be prevented to some degree (McLatchie 1977). It is, therefore, recommended that a doctor, preferably one interested in sports medicine, be in attendance at karate competitions. Further it is also possible to have in attendance a representative from Red Cross, St. John or St. Andrew Ambulance service, provided these excellent voluntary bodies are given prior notice.

\section{RESPONSIBILITIES OF THE MEDICAL OFFICER}

A doctor should attend where $\mathbf{2 0}$ or more karatekae compete. His duties shall be to examine competitors before the competition if requested by officials. The fighting areas should be inspected to ascertain that adequate flooring is in use. It is recommended that padded flooring should be used since head injury is a common sequel to falls on hard floors (Schmid et al 1968). ${ }^{*}$

He should also treat any minor injuries received, such as lacerations and sprains, but should refer more serious injuries for hospital examination. Further the medical officer present should be able to advise the referees, where requested, as to the fitness of a competitor to continue in a competition and also as to the potential of various techniques when dubious points are under discussion.

\section{INJURIES WHICH EXCLUDE FURTHER PARTICIPATION}

1. Bony fractures.

2. Head injuries which have resulted in disorientation, amnesia or unconsciousness.

3. Ocular injuries when sight is impaired. This includes the periorbital injuries (haematomata, lacerations) and is dependent upon examination.

Address for Correspondence:

73 Novar Drive, Hyndland, GLASGOW
4. Certain cases of testicular injury where recovery is not rapid and scrotal haematomata are present.

\section{PROTECTIVE CLOTHING}

Each competitor should wear a groin guard. Gum shields and padding to the fists and shins are also recommended.

*I attended the Scottish Championships in October 1978 and was horrified to find that a stone floor was in use. I expressed my displeasure at this but the fights continued. One boy was knocked out with a punch, fell backwards and crushed his occiput on the floor. He required admission to the neuro-surgical unit of the Southern General hospital. The karate officials are now taking notice of padded flooring!

Many competitors have the habit of turning up the sleeves of their karate suits. This I think is a dangerous practice since finger or thumb injuries can result from digits being caught in the fold of the suits. Further many competitors nowadays have pierced ears and wear ear rings. It is mandatory that such 'jewellery' should be removed before any competition takes place.

\section{FITNESS TO COMPETE}

1. Following a knock-out a period of at least 4 weeks should be allowed to elapse before any further competition.

2. After serious ophthalmic injuries or aural injury a period of at least 6 weeks should be allowed to elapse before further competition or such time as is indicated by expert opinion, e.g. ophthalmic/ENT specialist. In such a case the competitor will be required to produce evidence of his fitness to compete.

3. Following bony injuries to the face, nose or hands a reasonable period of at least 6 weeks must be allowed to elapse depending on the nature of the injury and this will be subject to further medical examination.

\section{INTERNATIONAL COMPETITION}

Competitors should have a full medical examination before fighting. If travelling abroad the medical officer should make it his responsibility to ascertain the medical regulations of the host country and arrange vaccinations. He should also be able to advise governing bodies about estimated periods of acclimatisation in the host country. 


\section{CONTACT KARATE}

This sport should be subject to the same stringent medical measures as boxing (Graham, 1963). All competitors are required to satisfy a strict medical examina- tion and the use of padded floors and padded footwear is to be encouraged. Serious injuries have resulted from spinning kicks and it is believed that such techniques should be outlawed since they are uncontrollable once initiated.

\title{
REFERENCES
}

Graham, J. W. 1963. "Medical Care of the Boxer" in Medical Aspects of Boxing. Proceedings of a Conference held at Goldsmiths College, London, Nov. 1963. 85-91.

McLatchie, G. R. 1976. "Analysis of Injuries in 295 Karate Contests". British Journal of Accident Surgery 8: 132-134.

McLatchie, G. R. 1977. “Prevention of Karate Injuries - A Progress Report”. Brit.J.Sports Med. 11: 78-82.

Schmid, L., Hajek, E., Votipka, F., Teprik, O., Blonstein, J. L. 1968. "Experience with headgear in boxing." J.Sports Med.Phys.Fitness. 8: 171.

\author{
ADVANCE NOTICE \\ (Berkshire Area Health Authority - East District) \\ FARNHAM PARK REHABILITATION CENTRE \\ Farnham Park, Farnham Royal, Bucks., SL2 3LR Tel.: Farnham Common 2271/2 \\ COLLOQUIUM ON CLINICAL PROBLEMS PECULIAR TO SPORT \\ (Under the aegis of B.A.S.M. and B.A.R.R.)
}

The Third Windsor Colloquium on "Clinical Problems Peculiar to Sport" will be held at the Postgraduate Centre of the King Edward VII Hospital, Windsor, on 7th and 8th November 1979. The format of the meeting will be much as before, that is to say a number of presentations followed by short papers and discussions in each subject.

The central Symposium of the Colloquium will be on The Management of the Unstable Knee and on this occasion there will be an overseas guest lecturer, Prof. Ejnar Eriksson from the Karolinska in Stockholm, who will act as Moderator for the Symposium.

On this occasion the numbers of participants will be increased to a maximum of 50 . Further details will be forwarded to British Journal of Sports Medicine as soon as they have been clarified.

Reservations and enquiries to: J. G. P. Williams, Esq., MSc, FRCS, DPhysMed 